\title{
Language recovery and evidence of residual deficits after nonthalamic subcortical stroke: A 1 year follow-up study
}

\author{
Claudia Peñaloza a, *, Antoni Rodríguez-Fornells a, b, c, \\ Francisco Rubio ${ }^{\mathrm{d}}$, Maria Angeles De Miquel ${ }^{\mathrm{e}}$, \\ Montserrat Juncadella ${ }^{\mathrm{d} \text {, * }}$
}

${ }^{\text {a }}$ Cognition and Brain Plasticity Group, Bellvitge Biomedical Research Institute - IDIBELL, L'Hospitalet de Llobregat, Barcelona, 08097, Spain

${ }^{\mathrm{b}}$ Department of Basic Psychology, Campus Bellvitge, University of Barcelona, L'Hospitalet de Llobregat, Barcelona, 08097, Spain

c Catalan Institution for Research and Advanced Studies, ICREA, Barcelona, Spain

${ }^{\mathrm{d}}$ Department of Neurology, Hospital Universitari de Bellvitge - HUB, Campus Bellvitge, University of Barcelona, L'Hospitalet de Llobregat, Barcelona, 08097, Spain

e Department of Neuroradiology, Hospital Universitari de Bellvitge - HUB, Campus Bellvitge, University of Barcelona, L'Hospitalet de Llobregat, Barcelona, 08097, Spain

\section{A R T I C L E I N F O}

\section{Article history:}

Received 6 November 2013

Received in revised form 1 August 2014

Accepted 1 August 2014

Available online

\section{Keywords:}

Language

Aphasia

Recovery

Subcortical stroke

\begin{abstract}
A B S T R A C T
A variety of language disturbances including aphasia have been described after subcortical stroke but less is known about the factors that influence the long-term recovery of stroke-induced language dysfunction. We prospectively examined the role of the affected hemisphere and the lesion site in the occurrence and recovery of language deficits in nonthalamic subcortical stroke. Forty patients with unilateral basal ganglia stroke underwent language assessment within 1 week, 3 months and 1 year after stroke. Disturbances in at least one language domain were observed in 35 patients during the first week post stroke including aphasia diagnosed in 11 patients. Importantly, the appearance of deficits after stroke onset and the improvement of language function were not determined by the site of subcortical lesion, but instead were critically influenced by the affected hemisphere. In fact, the language impairments following left and right basal ganglia stroke mirrored the language dysfunction observed after cortical lesions
\end{abstract}

\footnotetext{
* Corresponding authors. Tel./fax: +34 934020993.

E-mail addresses: cpenaloza@idibell.cat, claudia_penaloza@hotmail.com (C. Peñaloza), mjuncadella@bellvitgehospital.cat (M. Juncadella).
} 
in the same hemisphere. A significant overall language improvement was observed at 3 months after stroke, although residual deficits in language executive function were the most commonly observed impairment at 1 year follow-up. Although a substantial improvement of language function can be expected after nonthalamic subcortical stroke, our findings suggest that language recovery may not be fully achieved at 1 year post stroke.

๑) 2014 Elsevier Ltd. All rights reserved.

\section{Introduction}

Over the last few decades a number of studies have focused on the role of the basal ganglia (BG) in language processing and the presence of language impairment following subcortical vascular damage. Lesion studies have reported aphasia in the face of vascular subcortical lesions elucidating deficits in almost every component of language in varying degrees of severity (see Nadeau \& Crosson, 1997 for a review). Lesion location has long been believed to be the major determinant of the clinical characteristics of aphasia (Godefroy, Dubois, Debachy, Leclerc, \& Kreisler, 2002). However, the lesion site of subcortical stroke cannot be reliably associated with aphasia (Wallesch, Johannsen-Horbach, Bartels, \& Herrmann, 1997) and lesion volume cannot predict its clinical type or degree of severity (Nadeau \& Crosson, 1997). Moreover, subcortical infarcts do not usually generate the typical aphasic syndromes (Copland, Chenery, \& Murdoch, 2000; Naeser et al., 1982) and some cases with no language deficits have been reported (Nadeau \& Crosson, 1997). The present study aimed to prospectively examine the language profiles of a large sample of patients with non-thalamic subcortical stroke from the subacute stage to 1 year post onset. We further aimed to compare the language performance of patients with left versus right hemispheric subcortical lesions in order to examine the contribution of the affected hemisphere to the appearance of language impairment.

Most of the available literature on subcortical stroke has predominantly focused on the language disturbances typically appearing after left hemisphere (LH) cortical damage. Previous studies with left BG stroke patients have reported deficits in different domains of speech and language function such as spontaneous speech, sentence comprehension, repetition, and naming (D'Esposito \& Alexander, 1995; Mega \& Alexander, 1994; Metter et al., 1983). Although these language abilities have been critically attributed to perisylvian cortical regions (Friederici, 2011; Hillis, 2007), their impairment has been also evidenced after BG stroke. For example, language deficits and dysarthria have been reported after ischemic lesions in the caudate nucleus (Kumral, Evyapan, \& Balkir, 1999). In addition, fluent aphasia, comprehension difficulties and phonemic paraphasias may follow large putamenal hemorrhages (D'Esposito \& Alexander, 1995). Language disturbances after left striatiocapsular lesions often involve fluent speech disturbances (Radanovic, Mansur, Azambuja, Porto, \& Scaff, 2004) and impairment in repetition and in naming with paraphasic errors (Nadeau \& Crosson, 1997). It has been also suggested that striatocapsular and white matter periventricular lesions are more strongly associated with phonetic than semantic impairment (Kuljic-Obradovic, 2003). Nevertheless, it is worth noting that the presence of language impairment after BG stroke is not unequivocal. Other studies have suggested that caudate (Caplan et al., 1990) and putamenal lesions are infrequently associated with aphasic symptoms (Damasio, Damasio, Rizzo, Varney, \& Gersh, 1982; Metter et al., 1986), and language function can remain mainly preserved after striatocapsular stroke (Benson \& Ardila, 1996; Kuljic-Obradovic, 2003). Thus, the occurrence of deficits in different language domains after left BG stroke is largely variable across studies, and inconsistently related to lesions in specific BG structures.

A different picture arises when considering the occurrence of language disturbance after vascular damage to the right hemisphere $(\mathrm{RH})$. Linguistic impairments related to discourse ability, pragmatics and prosody, and low performance in lexical-semantic processes, metaphor comprehension and receptive prosody have been described in the presence of RH cortical stroke (Jodzio, Lojek, \& Bryan, 2005). Although some cases with such language disturbances after subcortical lesions in the RH 
have been reported (Cohen, Riccio, \& Flannery, 1994; Radanovic \& Scaff, 2003) studies addressing these deficits are rare, and further research is clearly needed.

Importantly, although infrequently studied, deficits following subcortical stroke may also involve different aspects of language executive function and verbal short-term memory (STM)/working memory (WM) which are critically supported by the frontal lobes (Alvarez \& Emory, 2006; Baddeley, 2003a). Verbal fluency has been traditionally considered a component of executive function (Mitrushina, Boone, Ramazi, \& D'Elia, 2005). Semantic verbal fluency entails complex aspects of executive language ability such as the strategic search and retrieval of the right semantic representations, monitoring and cognitive flexibility (Ardila, Ostrosky-Solís, \& Bernal, 2006; Mitrushina et al., 2005; Troyer, Moscovitch, \& Winocur, 1997). Semantic fluency tests are sensitive to frontal lobe dysfunction after either left or right cortical injury (Baldo \& Shimamura, 1998). Yet, impaired performance in tests measuring verbal fluency and word generation has also been reported in patients with BG stroke (de Boissezon et al., 2005; Kuljic-Obradovic, 2003; Mega \& Alexander, 1994; Radanovic et al., 2004).

STM/WM is a cognitive domain crucially related to language processing. The phonological store and the rehearsal component of verbal STM are essential for the retention of information over short periods of time (Baddeley, Gathercole, \& Papagno, 1998) and the manipulation of verbal information is necessary for different complex cognitive abilities (Baddeley, 2003a). Broca's area and the dorsolateral prefrontal cortex (DLPFC) support the rehearsal and manipulation of items in verbal STM/WM (Baddeley, 2003b; Petrides, 2000). Previous studies of BG stroke have reported cases with deficits in verbal STM span tests (Cappa et al., 1997; Su, Chen, Kwan, Lin, \& Guo, 2007; Vallar et al., 1988). Furthermore, verbal STM/WM capacity can critically influence comprehension ability (Caplan \& Waters, 1999; Vallar \& Baddeley, 1987). The impairment of verbal comprehension of complex material related to an increase of STM/WM load has been previously reported in patients with striatocapsular stroke (Radanovic et al., 2004).

The occurrence of verbal fluency and STM/WM deficits after BG stroke is plausible given the wellestablished connections between the BG and the frontal cortex through different BG-thalamocortical pathways (Alexander, DeLong, \& Strick, 1986; Middleton \& Strick, 2000). The caudate nucleus receives input from the DLPFC through corticostriate projections (Alexander et al., 1986). This region is involved in executive functions including information monitoring in STM/WM (Petrides, 2005). Also, the left pre-supplementary motor area (pre-SMA) provides bilateral input to the caudate and putamen nuclei (Inase, Tokuno, Nambu, Akasawa, \& Takada, 1999). The left pre-SMA has been related with verbal WM (Crosson et al., 1999) and fMRI studies have evidenced the activation of different components of the left pre-SMA-BG-ventral anterior thalamic loop in word generation tasks (Crosson et al., 2003).

It has been suggested that executive dysfunction can be expected after lesions to the components of the frontostriatal circuits (Cummings, 1993) as they are anatomically and functionally related (Groenewegen, Berendse, Wolters, \& Lohman, 1990; Parent, 1990). Neurodegenerative disorders provide further evidence of executive dysfunction after BG pathology. Patients with Parkinson's disease commonly present impaired performance in executive function measures including verbal fluency and WM (Zgaljardic, Borod, Foldi, \& Mattis, 2003). These executive deficits have been related to dopamine depletion in the caudate nucleus that interrupts the normal activity in the frontostriatal circuitry (Lewis, Dove, Robbins, Barker, \& Owen, 2003; Owen, 2004). Similarly, the executive impairments reported in patients with Huntington's disease (Montoya, Price, Menear, \& Lepage, 2006) might be accounted for by the progressive degeneration of the caudate nucleus which receives prefrontal projections (Alexander et al., 1986). These findings suggest that executive dysfunction should also be expected after focal injury to the BG.

As reviewed here, much of the evidence of language impairment occurring after BG stroke comes from cross-sectional studies. However, it remains unclear how patients with subcortical damage recover from language dysfunction in the long-term. Only a few longitudinal studies based on clinical descriptions with accompanying neuroimaging data have been conducted to determine the recovery pattern of language dysfunction in subcortical stroke. Vallar et al. (1988) studied the evolution of 8 patients up to 6 months after BG stroke. The six patients who initially presented aphasia exhibited substantial recovery although residual language deficits were evidenced at the final assessment. Fromm, Holland, Swindell, and Reinmuth (1985) prospectively studied 16 cases for 22 weeks after subcortical stroke and found that 11 patients with language and other cognitive deficits presented a 
significant recovery between the first 6 and 8 weeks from brain insult, with language improvement being more complete and rapid as compared to other cognitive deficits. However, de Boissezon et al. (2005) found that 7 patients with aphasia following subcortical stroke performed significantly below a control group in an overt noun and verb generation task at one year-follow up, suggesting that language recovery was not fully completed at this time point.

In summary, the language deficits due to nonthalamic subcortical stroke are largely variable and a unitary profile of language impairment has not been clearly defined on the basis of the BG injured. Only a few longitudinal studies have addressed the evolution of language dysfunction beyond the subacute phase of stroke. However, residual deficits in the long term have only been examined in small samples and the role of the affected hemisphere in the occurrence and recovery of language impairment remains unclear. The present study aimed to examine the occurrence and long-term recovery of language deficits in a large cohort of patients with nonthalamic unilateral subcortical stroke, while prospectively addressing the role of the hemispheric localization and the site of the lesion in language recovery from the subacute stage to one year post stroke. We also explored the occurrence and recovery of verbal STM impairment and its relationship with comprehension of complex verbal material. We expected that although patients would not be clearly differentiated according to the site of the lesion, the language impairment in the group of patients with LH stroke would be more severe and qualitatively different from that observed in the RH group. Accordingly, we expected that the hemisphere but not the specific BG structures affected by the lesion would be critical to clearly differentiate the language recovery in our patients at the 3 time points of assessment. Given the abovementioned evidence that executive function relies on components of the frontal lobe-BG connections, we expected the occurrence of deficits in language processes relying on executive function and hypothesized that the pattern of recovery of such processes would be different from the recovery of the lexical-semantic functions supported by perisylvian cortical regions. In addition, we expected that residual deficits would continue to be observed at 1 year follow-up.

\section{Methods}

\subsection{Participants}

The participants were 59 patients admitted to the Neurology unit of the Hospital Universitari de Bellvitge, L'Hospitalet de Llobregat in Barcelona, Spain presenting a subcortical stroke identified on computerized tomography (CT). Patients were continuously included into the final sample over a period of 30 months. The inclusion criteria were: i) first and single nonthalamic subcortical stroke, ii) vascular lesion in either the caudate nucleus with or without involvement of adjacent BG nuclei, or in any other BG nuclei (with or without impairment to adjacent white matter pathways in both cases), iii) ischemic and hemorrhagic etiology, iv) neurological condition and cognitive status stable enough to allow the completion of language assessment. Exclusion criteria were: i) evidence of cortical lesions, and ii) history of neurological or psychiatric disorders.

We discarded 13 patients from the initial sample because cortical lesions in frontal and temporal regions were found on MRI scans at 3 months post stroke. At this time point, 6 patients with lesions in the thalamus were excluded, as their MRI scans evidenced that the BG structures remained spared. The final sample consisted of 40 patients ( 32 male), ages ranging between 18 and 75 ( $M=54.1$ years; $\mathrm{SD}=15.68)$. The mean number of educational years was $6.65(\mathrm{SD}=2.66)$. Patients were predominantly right-handed and only cases 11 and 22 showed a tendency to ambidexterity as assessed with the Edinburgh Handedness Inventory (EHI, Oldfield, 1971). All patients were Spanish native speakers. Of these, 31 patients were bilinguals and had learned Catalan as their second language, whereas 9 patients were monolinguals for Spanish. The remaining patients only spoke Spanish.

Lesions in the $\mathrm{LH}$ were as frequent as lesions in the $\mathrm{RH}$, affecting 20 patients in each group. There were no significant differences in age [LH lesion $M=56.25, \mathrm{SD}=16.39$; $\mathrm{RH}$ lesion $M=51.95$, $\mathrm{SD}=15.05 ; t(38)=-.86, p=.39$ ] or years of education [LH lesion $M=6.4$, SD $=2.93$; $\mathrm{RH}$ lesion $M=6.9, \mathrm{SD}=2.42 ; t(38)=.58, p=.56$ ] between patients with a left-sided lesion and those with a right-sided lesion. Similarly, we found no significant differences in age [caudate nucleus $M=52.65$, $\mathrm{SD}=15.57$; other $\mathrm{BG}$ nuclei $M=55.55, \mathrm{SD}=16.06 ; t(38)=-.58, p=.56$ ] or years of education [caudate 
nucleus $M=6.45$, SD $=2.91$; other $\mathrm{BG}$ nuclei $M=6.85$, $\mathrm{SD}=2.45 ; t(38)=-.47, p=.64$ ] between patients with lesions in the caudate nucleus and patients with lesions in other BG nuclei.

There were no significant differences in lesion volume when comparing patients according to the hemisphere of the lesion [LH lesion $M=4.55, \mathrm{SD}=1.88$; $\mathrm{RH}$ lesion $M=4.25, \mathrm{SD}=1.97 ; t(38)=-.49$, $p=.62$ ] or the lesion site [caudate nucleus $M=3.95, \mathrm{SD}=1.76$; other $\mathrm{BG}$ nuclei $M=4.85, \mathrm{SD}=1.98$; $t$ $(38)=-1.51, p=.14]$. The mean volume of the lesion for the total sample was $4.04 \mathrm{~cm}^{3}(\mathrm{SD}=1.9)$.

Ischemic lesions affecting the caudate nucleus (75\%) were more frequently observed than hemorrhagic lesions (25\%). Conversely, hemorrhagic lesions (80\%) were more common in patients with lesions involving other BG nuclei than ischemic lesions (20\%). Table 1 summarizes the subcortical structures and adjacent pathways affected in the overall sample (also see Fig. 1 for CT and MRI scans of four representative cases). All procedures were conducted in accordance with the Declaration of Helsinki and were approved by the Committee of Ethics for Clinical Research of the Hospital Universitari de Bellvitge. Patients gave their informed written consent.

\subsection{Language and STM assessment}

All patients underwent a battery of tests addressing different aspects of language. Five subtests included in the Integrated Program of Neuropsychological Examination- Revised Barcelona Test (PeñaCasanova, 2005) were used to evaluate different language abilities. The Conversational narrative speech test was used to examine speech fluency and information content in spontaneous speech. It consists of a conversation based on eight standardized open questions regarding personal, familiar and stroke related information. The Picture description test is a measure of spontaneous narrative speech that constrains the production of connected speech to a specific pictured context (Bird, Lambon Ralph, Patterson, \& Hodges, 2000). It is also informative of discourse function deficits as structured tasks of high complexity may intensify deficits in the presence of RH lesions (Joanette \& Goulet, 1990) otherwise not observed in more natural conversational contexts. This measure includes one picture that requires the description of six events in a family scene. Language executive function was evaluated using a semantic verbal fluency test. The Animal naming fluency test is a word generation task that involves producing as many animal names as possible in one minute. This task allowed evaluating the ability of patients to accurately select, retrieve and produce several items of a common semantic category in a reduced time period. Auditory comprehension was assessed with the Commands test. It includes five instructions that measure the ability to process an increasing number of units of auditory information and to perform the specific actions required. The Digit forward test of the same neuropsychological battery was also included to assess verbal STM and to determine the relationship between this ability and performance on the Token test. The Digit Forward test requires the immediate recall of strings of randomly arranged digits in the forward order. Additionally, the Token test (De Renzi \& Faglioni, 1978) was used to evaluate verbal comprehension of complex material. This test was

Table 1

Localization of lesions in the basal ganglia and adjacent white matter according to the hemisphere of the lesion.

\begin{tabular}{|c|c|c|c|c|c|c|c|c|c|c|c|}
\hline \multirow[t]{2}{*}{ Group } & \multirow[t]{2}{*}{ LH } & \multirow[t]{2}{*}{ RH } & \multirow[t]{2}{*}{ BG structure } & \multicolumn{4}{|c|}{$\begin{array}{l}\text { WM involved in LH } \\
\text { stroke }\end{array}$} & \multicolumn{4}{|c|}{$\begin{array}{l}\text { WM involved in } \mathrm{RH} \\
\text { stroke }\end{array}$} \\
\hline & & & & $\mathrm{CR}$ & $\mathrm{EC}$ & IC-AL & IC-PL & $\mathrm{CR}$ & EC & IC-AL & IC-PL \\
\hline Caudate/ & 0 & 1 & Caudate & 0 & 0 & 0 & 0 & 0 & 0 & 1 & 0 \\
\hline Caudate + other & 5 & 2 & Caudate + Putamen & 4 & 4 & 2 & 1 & 2 & 0 & 2 & 0 \\
\hline BG nuclei & 0 & 1 & Caudate + G. pallidus & 0 & 0 & 0 & 0 & 0 & 0 & 0 & 0 \\
\hline$(n=20)$ & 7 & 4 & Caudate + Putamen + G. pallidus & 6 & 3 & 3 & 4 & 4 & 2 & 2 & 2 \\
\hline \multirow{3}{*}{$\begin{array}{l}\text { Other BG nuclei }+ \\
\text { spared Caudate } \\
(n=20)\end{array}$} & 3 & 9 & Putamen & 2 & 3 & 0 & 0 & 5 & 6 & 0 & 3 \\
\hline & 0 & 1 & G. pallidus & 0 & 0 & 0 & 0 & 1 & 0 & 0 & 0 \\
\hline & 5 & 2 & Putamen + G. pallidus & 4 & 5 & 1 & 4 & 0 & 2 & 0 & 2 \\
\hline
\end{tabular}

Values represent the number of cases with lesions according to the hemisphere, basal ganglia structure, and white matter involvement.

$\mathrm{LH}=$ left hemisphere; $\mathrm{RH}=$ right hemisphere; $\mathrm{BG}=$ basal ganglia; $\mathrm{WM}=$ white matter; $\mathrm{CR}=$ corona radiate; $\mathrm{EC}=$ external capsule; IC-AL = internal capsule: anterior limb; IC-PL = internal capsule: posterior limb; G. pallidus = globus pallidus. 


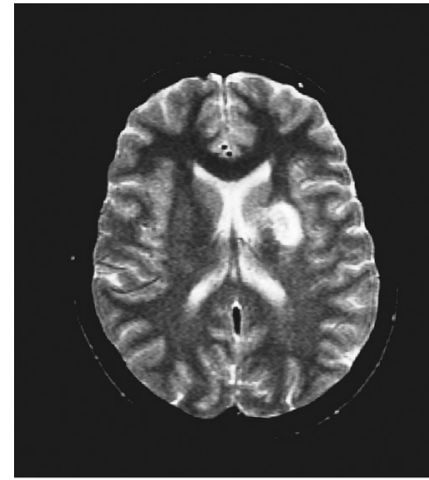

A

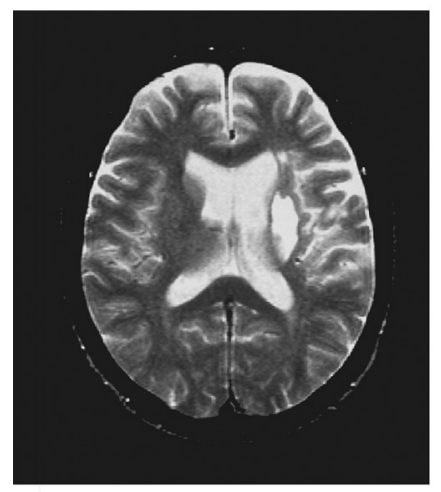

C

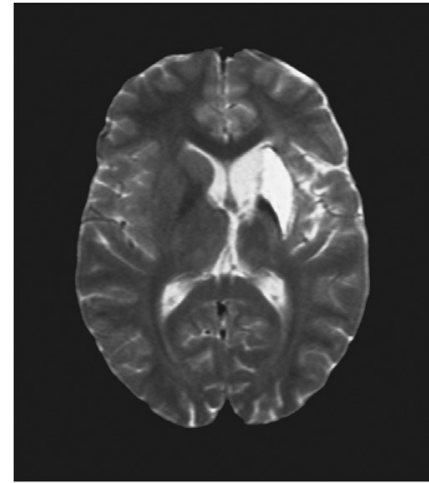

B

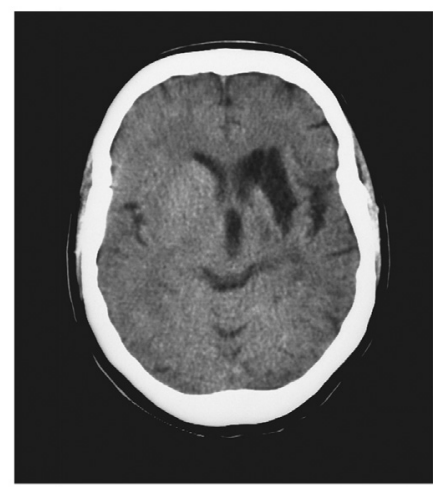

$\mathrm{D}$

Fig. 1. Structural scans and SPECT from representative cases. (A-B). T2-weigthed MRI scans of case 2 and case 20 showing an ischemic lesion involving the left caudate and putamen nucleus. (C) T2-weigthed MRI of case 4 with a left ischemic lesion in the putamen but spared caudate nucleus. (D) CT scan of case 36 with an ischemic lesion in the right caudate and putamen nucleus. Note that case 2 performed within the normal limits in all language tests whereas language dysfunction in the remaining cases ranged from mild language deficits (case 36) to severe aphasia (case 4) during the first week after stroke.

included in order to increase the complexity of verbal comprehension, as it loads on STM/WM because of the increasing number of lexical items (Friedmann \& Gvion, 2003). Naming ability was assessed with a 15-item short version of the Boston naming test (Calero, Arnedo, Navarro, Ruiz-Pedrosa, \& Carnero, 2002). All tests were administered in Spanish and the normative data for the Spanish population were available.

\subsection{Imaging protocol}

CT scans were performed with an Elscint CT unit (Elscint, Haifa, Israel) using serial slices of 5 and $10 \mathrm{~mm}$. Axial and coronal MRI $\mathrm{T}_{2}$-weighted images were obtained with a $0.5 \mathrm{~T}$ Philips scanner (Philips, Eindhoven, The Netherlands). Slice thickness for MRI scans was fixed at $7 \mathrm{~mm}$. MRI scans were used to determine the lesion site and volume in all patients, except for 2 cases with LH stroke (cases 6 and 11) for whom only CT scans were available. The lesion size was calculated using the summation-of-areas technique, a simple and practical mean of calculating lesion volumes (Breiman et al., 1982; Watson et al., 1992). First, the area of each lesion was calculated in each MRI or CT slice cut by measuring the two diameters of the lesion in non-round-shaped lesions or by calculating the circle area using the radius in round-shaped lesions. The resulting value was then multiplied by the slice thickness, which allowed obtaining the lesional tissue area in $\mathrm{cm}^{3}$. When the lesion was detected on different slices, the 
volume of each lesion was calculated by also adding the slice volumes. Given that the density or signal intensity of the internal capsule differs from that of the BG and the thalamus in MRI and CT imaging, the medial border of the posterior limb of the internal capsule was used as the landmark to delineate the lateral aspect of the thalamus, and to make distinctions between BG and thalamic lesions.

No intravenous contrast was used to obtain the CT scans or MRI images. CT and MRI scans were independently analyzed by one neuroradiologist and one clinical neurologist. The specialists were blinded to the results of neuropsychological testing and the evolution of patients.

\subsection{Procedure}

We prospectively evaluated all patients within the first week, at 3 months and at 1 year post stroke. The first assessment was conducted within the first 3-7 days from admission (hereafter, subacute stage). It included a CT scan at hospital admission and language testing. A second language assessment was conducted at 3-month post stroke after hospital dismissal. MRI studies were performed between the third and the fourth months post stroke. The third language assessment was conducted at 1 year follow-up.

All language tests were used at the three time points of assessment, except for the Token test which was only administered in the second and third evaluations. The lesion site and volume were determined using MRI and CT scans as previously described. The diagnosis of aphasia was determined by the professional judgment of a clinical neurologist and a neuropsychologist, using the classical aphasia syndrome descriptions (Goodglass \& Kaplan, 1983).

\subsection{Statistical analysis}

All analyses were conducted with SPSS Statistics 17.0. The direct scores of patients in the language tests at the three time points of assessment were considered as the dependent variables in all analyses. In order to explore the influence of the hemispheric localization of the lesion and the subcortical structures affected in the evolution of the linguistic performance of patients after stroke, we divided our sample according to i) the Hemisphere of the Lesion, namely left hemisphere (LH) and right hemisphere ( $\mathrm{RH})$, and ii) the Lesion site, namely caudate nucleus with or without involvement of other BG nuclei, and other BG nuclei excluding the caudate nucleus.

A one-way repeated measures ANOVA (Time $\times$ Group) with time $(t 1=$ subacute stage, $t 2=$ three months, $t 3$ = one year post stroke) defined as the intra-group variable and i) Hemisphere of the Lesion and ii) Lesion site as the inter-group variables was conducted for each dependent variable. When violations to sphericity were detected the Greenhouse and Geisser corrections were performed and the epsilon values were reported. When effects or interactions were considered statistically significant ( $p=.05$ or smaller), paired samples $t$-tests were used for intra-group comparisons and independent samples $t$-tests were conducted for inter-group comparisons. We also performed a Pearson correlation between the scores of the patients on the Digit forward test and those obtained on the Token test to determine the relationship between immediate STM and performance on auditory comprehension of complex verbal material. Statistical significance for these analyses was also set at the .05 level.

\section{Results}

\subsection{Language and STM status at the subacute stage of stroke}

The language and STM performance of stroke patients at the subacute stage of stroke is summarized in Appendix A in the supplementary materials. Aphasia was diagnosed in 11 patients (27.5\%) with an LH lesion (Table 2). In addition, 8 patients with an LH lesion did not receive a diagnosis of aphasia but presented deficits in different language domains. Only case 2 with an LH lesion performed within the normal limits in all tests. Performance below the cut-off scores was also registered in 16 patients with an RH lesion in all language tests except for the BNT, which evidenced a normal naming ability in all cases. Cases 23, 27, 29, and 33 in the RH group performed within the normal limits in all tests. Importantly, only patients with an RH lesion presented verbosity, with excessive information and irrelevant details that greatly impaired the structure of their narrative speech as evidenced in the 
Table 2

Demographic and clinical characteristics of patients with aphasia after left subcortical stroke at the subacute stage and at 1 year follow-up.

\begin{tabular}{|c|c|c|c|c|c|}
\hline Case & $\begin{array}{l}\text { Age/Gender/ } \\
\text { Ed. yrs/Language }\end{array}$ & Lesion site CT-MRI & $\begin{array}{l}\text { Type of lesion/ } \\
\text { volume }\left(\mathrm{cm}^{3}\right)\end{array}$ & $\begin{array}{l}\text { Aphasia type and severity } \\
\text { (1 week) }\end{array}$ & $\begin{array}{l}\text { Language status } \\
\text { (1 year) }\end{array}$ \\
\hline 1 & 58/F/5/Spanish & $\mathrm{C}-\mathrm{B} / \mathrm{P} / \mathrm{CR} / \mathrm{IC}-\mathrm{AL} / \mathrm{EC}$ & Ischemia $/ 4 \mathrm{~cm}^{3}$ & $\begin{array}{l}\text { Unclassifiable aphasia/ } \\
\text { moderate }\end{array}$ & $\begin{array}{l}\text { Unclassifiable aphasia/ } \\
\text { moderate }\end{array}$ \\
\hline 3 & 45/F/7/Spanish & $\begin{array}{l}\text { C-B/C-H/P/IC-PL/ } \\
\text { GP/CR }\end{array}$ & Ischemia $/ 6 \mathrm{~cm}^{3}$ & $\begin{array}{l}\text { Trans. motor aphasia/ } \\
\text { moderate }\end{array}$ & $\begin{array}{l}\text { Trans. motor aphasia/ } \\
\text { mild }\end{array}$ \\
\hline 4 & 60/M/5/Spanish & $\mathrm{P} / \mathrm{IC}-\mathrm{PL} / \mathrm{EC} / \mathrm{GP} / \mathrm{CR}$ & Ischemia $/ 6 \mathrm{~cm}^{3}$ & $\begin{array}{l}\text { Unclassifiable aphasia/ } \\
\text { severe }\end{array}$ & $\begin{array}{l}\text { Unclassifiable aphasia/ } \\
\text { moderate }\end{array}$ \\
\hline 7 & 48/M/8/Spanish & $\mathrm{P} / \mathrm{IC}-\mathrm{PL} / \mathrm{EC} / \mathrm{GP}$ & Hemorrhage $/ 5 \mathrm{~cm}^{3}$ & $\begin{array}{l}\text { Conduction aphasia/ } \\
\text { moderate }\end{array}$ & No aphasia \\
\hline 8 & 37/M/5/Spanish & C-B/P/IC-AL/EC/CR & Hemorrhage $/ 7 \mathrm{~cm}^{3}$ & $\begin{array}{l}\text { Unclassifiable aphasia/ } \\
\text { mild }\end{array}$ & $\begin{array}{l}\text { No aphasia, reduced } \\
\text { verbal fluency }\end{array}$ \\
\hline 9 & 63/M/5/Spanish & $\mathrm{P} / \mathrm{IC}-\mathrm{PL} / \mathrm{EC} / \mathrm{GP} / \mathrm{CR}$ & Hemorrhage $/ 5 \mathrm{~cm}^{3}$ & $\begin{array}{l}\text { Unclassifiable aphasia/ } \\
\text { mild }\end{array}$ & $\begin{array}{l}\text { No aphasia, reduced } \\
\text { verbal fluency }\end{array}$ \\
\hline 11 & 72/F/5/Spanish & $\mathrm{C}-\mathrm{B} / \mathrm{P} / \mathrm{EC} / \mathrm{GP} / \mathrm{CR}$ & Ischemia $/ 4 \mathrm{~cm}^{3}$ & Broca's aphasia/severe & $\begin{array}{l}\text { Trans. Motor aphasia/ } \\
\text { moderate }\end{array}$ \\
\hline 12 & 58/M/5/Spanish & C-H/P/IC-AL/GP & Ischemia $/ 2 \mathrm{~cm}^{3}$ & $\begin{array}{l}\text { Trans. motor aphasia/ } \\
\text { mild }\end{array}$ & $\begin{array}{l}\text { No aphasia, reduced } \\
\text { verbal fluency }\end{array}$ \\
\hline 18 & $\begin{array}{l}50 / \mathrm{M} / 12 / \\
\text { Bilingual }\end{array}$ & $\begin{array}{l}\mathrm{C} / \mathrm{P} / \mathrm{IC}-\mathrm{AL} / \mathrm{EC} / \mathrm{GP} / \\
\mathrm{CR}\end{array}$ & Ischemia $/ 4 \mathrm{~cm}^{3}$ & $\begin{array}{l}\text { Mixed Trans. aphasia/ } \\
\text { moderate }\end{array}$ & $\begin{array}{l}\text { No aphasia, reduced } \\
\text { verbal fluency }\end{array}$ \\
\hline 19 & 73/M/5/Spanish & $\mathrm{P} / \mathrm{EC} / \mathrm{CR}$ & Hemorrhage $/ 4 \mathrm{~cm}^{3}$ & $\begin{array}{l}\text { Mixed Trans. aphasia/ } \\
\text { mild }\end{array}$ & $\begin{array}{l}\text { No aphasia, reduced } \\
\text { verbal fluency }\end{array}$ \\
\hline 20 & $\begin{array}{l}\text { 18/M/10/ } \\
\text { Spanish }\end{array}$ & $\begin{array}{l}\text { C/P/IC-AL/IC-PL/ } \\
\text { GP/CR }\end{array}$ & Ischemia $/ 7 \mathrm{~cm}^{3}$ & $\begin{array}{l}\text { Trans. sensory aphasia/ } \\
\text { moderate }\end{array}$ & $\begin{array}{l}\text { No aphasia, reduced } \\
\text { verbal fluency }\end{array}$ \\
\hline
\end{tabular}

Ed. yrs. = Educational years; $\mathrm{F}=$ female; $\mathrm{M}=$ male; $\mathrm{C}-\mathrm{B}=$ caudate: body; $\mathrm{C}-\mathrm{H}=$ caudate: head; $\mathrm{P}=$ putamen; $\mathrm{CR}=$ corona radiata; $\mathrm{IC}-\mathrm{AL}=$ internal capsule: anterior limb; $\mathrm{IC}-\mathrm{PL}=$ internal capsule: posterior limb; $\mathrm{EC}=$ external capsule; $\mathrm{GP}=\mathrm{globus}$ pallidus; Trans $=$ transcortical.

Picture description test. The most frequently observed deficit in the overall sample involved verbal fluency observed in 72.5\% patients. Verbal STM performance was impaired in 9 patients with LH stroke and only 3 patients with RH stroke performed below the normal limits on this measure.

\subsection{Language and STM status over time}

The main and interaction effects of each repeated measures ANOVA of the linguistic performance of patients over time are summarized in Table 3. The first ANOVAs included the within-subject factor Time ( 3 levels) and the Hemisphere of the Lesion as the group variable. There was a significant main effect of Time in all the language and STM measures over follow-up assessment. Language performance of the overall sample showed a similar pattern of evolution over time, with a remarkable increment of scores between the subacute stage and the assessment at 3 months, and a tendency to continue improving performance between 3 months and 1 year post stroke. The ANOVAs also revealed a main

Table 3

One way repeated measures ANOVA analyses for performance of patients in language tests at the three time points of assessment after stroke.

\begin{tabular}{|c|c|c|c|}
\hline Language test & Time & Hemisphere & Time $\times$ Hemisphere \\
\hline $\begin{array}{l}\text { Conversational narrative } \\
\text { speech test }\end{array}$ & $F=(2,76)=11.27, p=.001$ & $F=(1,38)=7.33, p=.010$ & $F=(2,76)=9.72, p=.002$ \\
\hline Picture description test & $F=(2,74)=30.07, p=.000$ & $F=(1,37)=6.52, p=.015$ & $F=(2,74)=2.10, p=.146$ \\
\hline Boston naming test & $F=(2,74)=11.02, p=.001$ & $F=(1,37)=10.01, p=.003$ & $F=(2,74)=5.27, p=.020$ \\
\hline Commands test & $F=(2,76)=15.22, p=.000$ & $F=(1,38)=6.26, p=.017$ & $F=(2,76)=7.36, p=.007$ \\
\hline Token test & $F=(1,38)=5.61, p=.023$ & $F(1,38)=11.17, p=.002$ & $F=(1,38)=3.89, p=.056$ \\
\hline Animal naming fluency test & $F=(2,76)=16.68, p=.000$ & $F=(1,38)=9.04, p=.005$ & $F=(2,76)=1.63, p=.207$ \\
\hline Digit forward test & $F=(2,76)=3.91, p=.024$ & $F=(1,38)=2.87, p=.098$ & $F=(2,76)=1.99, p=.144$ \\
\hline
\end{tabular}

Effects and interactions significant at the .05 level (two-tailed) are shown in bold. 
effect of Group in all language measures evidencing that the performance of the LH group was below the RH group in all language and STM tests (Fig. 2).

Importantly, two different patterns of results were observed when considering the Hemisphere of the Lesion. A first pattern was revealed by the significant interaction between Time and Hemisphere of the Lesion found in the Conversational narrative speech test, the BNT, and the Commands test (Table 3). The LH group showed a great recovery in these measures over the first 3 months as the performance of this group was no longer significantly different from that observed in the RH group at this time point and onwards (Fig. $2-\mathrm{A}$ ).

A second pattern of results was observed in the Picture description test, the Token test and the Animal naming fluency test, where the LH group continued to perform significantly below the RH group beyond the assessment at 3 months (Fig. 2 - B). This was clearly evidenced by the nonsignificant interaction effects of Time $\times$ Hemisphere of the Lesion in these tests. However, these measures showed different trends of recovery over time after the 3 month-assessment. The analysis of the Picture description test evidenced that the LH group that had performed significantly below the RH group at the subacute stage and at 3 months, no longer differed from this last group at 1 year follow-up. As regards to performance on the Token test, the LH group remained significantly below the RH group at both the 3-month and 1-year follow-up assessments. Finally, the performance of the two groups on the Animal naming fluency test was not significantly different at 3 months assessment, although this difference between groups became significant at 1 year. At this time point, the performance of the $\mathrm{RH}$

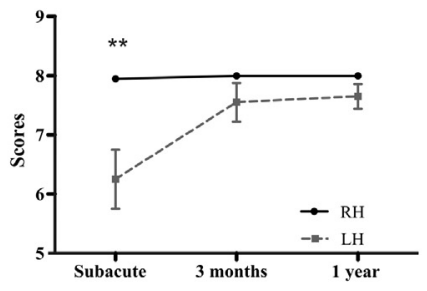

Conversational narrative speech test

A

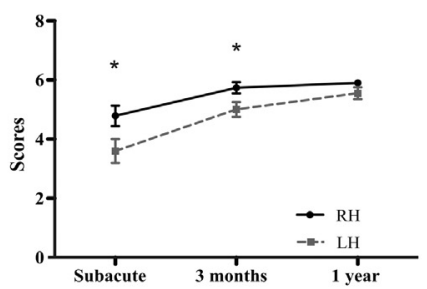

Picture description test
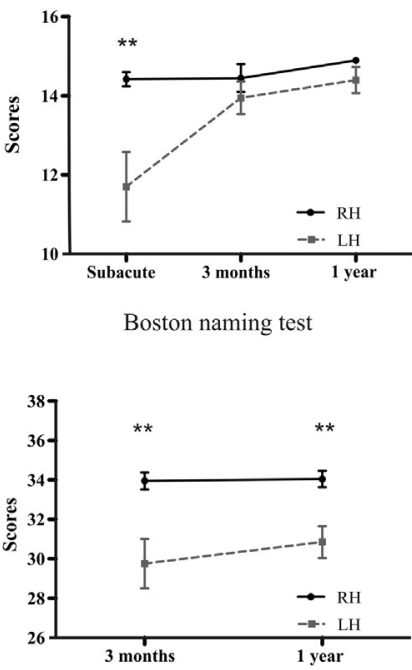

Token test

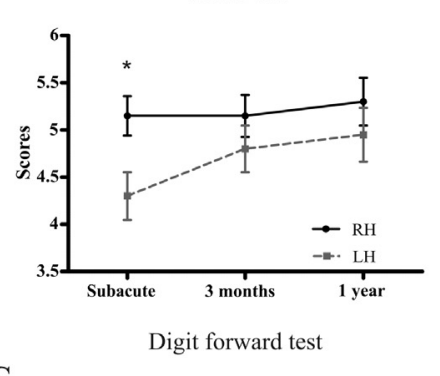

C
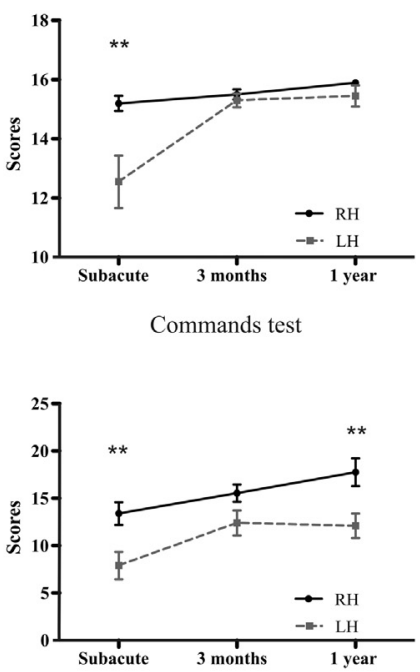

Animal naming fluency test

B

Fig. 2. Performance of patients with an LH lesion versus patients with an RH lesion in language and verbal STM testing over time. Independent sample $t$-tests between the two groups achieving statistical significance are depicted as ${ }^{*} p<.05$, ${ }^{* *} p<.01$. 
group on this measure continued to improve, while the LH group showed a tendency to improve scores at 3 months but failed to keep on improving afterwards.

The repeated measures ANOVA of the Digit forward test evidenced a significant main effect of Time but different from the language measures abovementioned, the main effect of Group was nonsignificant (Table 3). These results suggest that the improvement on this STM measure occurred in the overall sample of patients regardless the Hemisphere of the lesion (Fig. 2 - C). Importantly, we found a significant correlation between performance on the Digit forward test and the Token test at 3 months $(r=.49, p=.001)$ and 1 year assessments $(r=.53, p<.001)$ suggesting a close relationship between verbal STM performance and verbal comprehension of complex material.

As regards to the evolution of the language performance of patients with an RH lesion, $t$-tests revealed a significant difference in scores between the subacute stage and 1 year for the Picture description test [ $t(18)=-3.41, p=.003$ ], the BNT [ $t(18)=-2.96, p=.008$ ], the Commands test [ $t$ $(19)=-2.67, p=.015]$ and the Animal naming fluency test $[t(19)=-3.33, p=.004]$ pointing to a significant improvement over time. However, no significant differences were found between their scores at the subacute stage and at 1 year on the Conversation narrative speech test $[t(19)=-1$, $p=.33]$, the Token test $[t(19)=-1.45, p=.16]$ or the Digit forward test $[t(19)=-.68, p=.50]$.

A second ANOVA analysis was conducted with the within-subject factor Time (3 levels) and the Lesion site as the group variable. This ANOVA showed no significant effects of Lesion site on the performance of patients over time in the Conversational narrative speech test $[F(1,38)=.004, p=.953]$, the Picture description test $[F(1,37)=.131, p=.72]$, the Boston naming test $[F(1,37)=.13, p=.72]$, the Commands test $[F(1,38)=.004, p=.95]$, the Token test $[F(1,38)=.004, p=.949]$, the Animal naming fluency test $[F(1,38)=.003, p=.953]$, or the Digit forward test $[F(1,38)=1.95, p=.171]$.

\subsection{Language and STM status at 1 year follow-up}

The language and STM performance of stroke patients at 1 year follow-up is presented in Appendix $B$ in the supplementary materials. The assessment at 1 year post stroke showed that 7 out of 11 patients who presented aphasia at the subacute phase achieved language recovery to some extent although mild residual deficits were still evidenced. Among the aphasic patients, only case 7 performed within the normal limits in all language measures, whereas 6 patients continued to present deficits in verbal fluency despite their normal performance in the other tests. The remaining 4 patients showed little improvement and continued to present aphasia at 1 year (Table 2). The performance of the non-aphasic patients with an LH lesion remained below the normal limits in four cases. Conversely, patients with an RH lesion performed within the normal limits in the Conversational narrative speech test, BNT, and the Token test. However, 8 patients scored below the cut-off in the Animal naming fluency test. Although verbal STM remained impaired in 4 patients with an LH lesion and in 4 patients with an RH lesion, most patients in the LH group displayed a rather low STM performance within the normal limits. The most common residual deficit in the overall sample involved verbal fluency which continued below normal performance in $52.5 \%$ patients at 1 year.

\section{Discussion}

We prospectively studied the occurrence and recovery of language and verbal STM dysfunction in a large cohort of 40 patients with nonthalamic unilateral subcortical stroke from the subacute phase to 1 year post stroke. Our main findings indicate that the language deficits observed at the subacute stage of stroke and their recovery were determined by the hemisphere of the lesion, and not by the locus of subcortical injury. Furthermore, although we evidenced an important recovery during the first 3 months, deficits in language executive function were the most commonly observed impairment at 1 year post stroke. These and other relevant findings are further discussed.

As expected, patients with lesions to the caudate nucleus did not clearly differ from those with lesions to other BG nuclei and spared caudate nucleus at baseline testing. Moreover, we did not find a significant effect of the BG affected (Lesion site) in the language improvement of the overall sample across different time points of assessment. These results support previous studies suggesting the absence of a single pattern of language deficits associated to vascular damage to the BG (Copland et al., 
2000; Nadeau \& Crosson, 1997) and highlight the role of the functional connections between the BG and the frontal lobes in the appearance of language dysfunction (Alexander et al., 1986; Middleton \& Strick, 2000) as discussed below.

Our findings revealed specific patterns of recovery according to the lesioned hemisphere. At baseline assessment, patients with an LH lesion scored below the cutoff showing a clear impairment to language ranging from mild isolated disturbances in single language domains to more severe deficits in the form of diagnosable aphasic syndromes. A first pattern of language recovery indicated that LH stroke patients achieved a significant language recovery at 3 months and still evident but reduced improvement onwards. This pattern of recovery was clearly evidenced by the interaction Time $\times$ Hemisphere observed in the evolution of spontaneous speech as measured by the Conversational narrative speech, verbal comprehension as measured by the Commands test, and naming ability as measured by the BNT, the language domains subserved by the perisylvian language cortex (Hillis, 2007) traditionally considered in the diagnosis of aphasia (Goodglass \& Kaplan, 1983). Previous studies have reported cases of language disturbance with similar characteristics resolving within the first 3 months post stroke (Fromm et al., 1985; Kumral et al., 1999; Vallar et al., 1988) while only a few patients achieved a significant improvement after this period (Liang et al., 2001). Indeed, mild deficits in these language domains can be detected beyond this time point, specially when using measures of higher complexity as evidenced by the Picture description test. In line with previous research, our findings suggest that there is a critical 3-month time window for significant spontaneous recovery of language function following LH nonthalamic subcortical stroke.

Conversely, most patients with an RH lesion performed within the normal limits in the Conversational narrative speech test, the BNT, and the Commands test and mild deficits were only detected in a few cases. As a group, patients with an RH stroke improved to near ceiling performance in these tests at the final assessment. Interestingly, only the Picture description test was useful to identify qualitatively different deficits from those observed in patients with an LH lesion. Baseline performance of patients with an RH lesion on this test was characterized by verbosity and tangential unelaborated fluent speech, poor in relevant content. Such deficits have been described as impairments to the discourse and pragmatic aspects of speech (Ferré, Ska, Lajoie, Bleau, \& Joanette, 2011) typically observed after RH cortical stroke (Blake, Duffy, Myers, \& Tompkins, 2002; Murteira \& Santos, 2012). Our findings suggest that the discursive aspects of language seemingly affected after right BG lesions return to be within the normal limits at 3 months post stroke.

These overall findings are in line with the idea that focal BG lesions are associated with impairments to functions of the same hemisphere (Schmahmann \& Pandya, 2008). Indeed, lesions to the left BG mimic the lexical-semantic dysfunction typically observed after damage to the cortical regions involved in the left language network (Middleton \& Strick, 2000), whereas lesions to the right BG impair the discourse and pragmatic aspects of language supported by the RH cortex that are crucial for social communication (Bookheimer, 2002). Although most of the existing literature concerns language dysfunction after LH subcortical stroke, our study offers evidence of the less frequently reported but clinically relevant deficits after RH subcortical lesion, and highlight the importance of formal language assessment in cases of right BG stroke.

The second pattern of recovery indicated that the performance of the LH group on the Animal naming fluency test and the Token test improved over the first 3 months but remained significantly below the RH group beyond this time point. Indeed, verbal fluency and verbal comprehension of complex material were not fully recovered at 1 year follow-up. These findings evidence the critical contribution of the BG-frontal cortex projections to more complex language processes (Alvarez \& Emory, 2006; Copland et al., 2000) that involve executive functions subserved by the prefrontal cortex (Stuss \& Levine, 2002).

Deficits in verbal fluency as measured by the Animal naming fluency test showed two different trends of recovery: while patients with an LH lesion progressed significantly within the first 3 months and failed to improve onwards, patients affected in the RH showed a continuous but less notorious improvement that only became considerable at 1 year. An impaired performance in this task has been associated with left frontal lobe impairment whereas mild defects may also appear in right frontal lobe pathology (Joanette \& Goulet, 1990). These differences in the degree of impairment and recovery according to the hemisphere of the lesion reflect a qualitatively different involvement of the BG in this 
language function. Although the BG are bilaterally involved in word generation, the left pre-SMA-BG ventral anterior thalamic loop has a role in word retrieval from lexical stores whereas the right BG have an inhibitory effect on the right frontal regions to prevent interference on language production (Crosson et al., 2003). Importantly, verbal fluency deficits were the most common impairment observed at 1 year, which supports the initial findings of de Boissezon et al. (2005) revealing that executive language recovery as measured by a word generation task was not fully completed at 1 year post stroke.

The performance of the patients with left BG lesions in the Token test remained significantly below that of patients with RH lesions at 3 months and 1 year after stroke. The scores of patients with an LH stroke on this test were critically hindered by the difficulty of the final part of the test involving more lexical items, which was not observed in patients with an RH lesion. Moreover, we found a significant correlation between the performance of the LH group on the Token test and the Digit forward test at 3 months and 1 year after stroke. This limited improvement in comprehension of complex verbal material in the LH group points to additional limitations in verbal STM as evidenced in previous studies (Radanovic et al., 2004). The frontal lobes hold a great structural overlap for verbal STM/WM and verbal processing (Hickok, 2009), and reduced verbal STM/WM capacity in aphasic patients correlates with verbal comprehension in high STM/WM load situations (Just \& Carpenter, 1992). The BG receive bilateral projections from the left pre-SMA (Inase et al., 1999) supporting verbal WM (Crosson et al., 1999; Mecklinger, Bosch, Gruenewald, Bentin, \& von Cramon, 2000) and fMRI studies have demonstrated the bilateral caudate involvement in verbal WM (Moore, Li, Tyner, Hu, \& Crosson, 2013). The general improvement of the overall sample in the Digit forward test irrespective from the lesioned hemisphere supports this bilateral involvement of the BG in verbal STM. Our findings suggest that the degree of impairment of verbal STM by virtue of a left BG lesion and concomitant disruption to this fronto-subcortical connection may influence performance and recovery of verbal comprehension of complex material.

These findings suggest that complex language processes related to executive function supported by the frontal lobes are more critically impaired in LH subcortical stroke than other language functions such as spontaneous speech, naming, and simple comprehension supported by perisylvian regions. Indeed, the language assessment at 1 year suggests that general language impairment achieves a more pronounced recovery than complex language processes related to executive function, being the later the most common residual deficits at 1 year post stroke, as suggested by previous studies (Fromm et al., 1985). The fact that language ability supported by frontal executive function is more critically impaired than lexical-semantic abilities subserved by other cortical regions seems rather reasonable given the role of the BG in the BG-thalamo-cortical circuits. A functional continuity between the BG and the frontal lobes within the frontostriatal pathways has been suggested (Dubois \& Pillon, 1996). While the frontal cortex is the primary neurological underpinning of executive function, the BG plays a crucial modulatory role in the cognitive functions subserved by this cortical region (Middleton \& Strick, 2000; Vallar et al., 1988). Thus, the occurrence of language executive deficits after BG pathology would reflect a functional derangement of the frontal cortex.

Although determining the causes of language recovery in our patient cohort was beyond the aim of this study, several factors can be considered as possible accounts. Language recovery following subcortical stroke has been associated with the improvement of cortical hypoperfusion with and without the use of reperfusion interventions (Hillis et al., 2002, 2004; Vallar et al., 1988). Our patient cohort did not receive any specific intervention to restore cortical perfusion at the acute stage, and the results reported reflect the natural progression of language recovery in patients who could not benefit from the currently available reperfusion treatments. Thus, it is possible that the residual presence of deficits in our patients is related to the initial presence of major cortical hypoperfusion in the frontal lobes and language perisylvian cortex and persistent hypoperfusion in the long term as evidenced in previous studies (Vallar et al., 1988).

It is also possible that damage to surrounding white matter pathways after subcortical stroke contributes to language dysfunction. For instance, there is evidence that lesions in the internal capsule may interrupt the functional cortico-subcortical connections (Alexander et al., 1986). It has been previously suggested that the degree of impairment and plasticity in the white matter fiber tracts relevant to language processing is also of great importance in predicting the recovery of language 
function (Naeser, Palumbo, Helm-Estabrooks, Stiassny-Eder, \& Albert, 1989; Schlaug, Marchina, \& Norton, 2009). Besides, language and speech therapy can lead to the reorganization of language neural networks accounting for brain plasticity in stroke survivors (Fridriksson, Richardson, Fillmore, \& Cai, 2012) even at the chronic phase (Meinzer et al., 2004). However, the information of language and speech therapy was not available in most cases reported in the present study and thus, we could not address its effects on language recovery.

\section{Conclusions}

Our findings indicate that the hemisphere of the lesion and not the specific structure of the vascular injury plays a key role in the occurrence of language deficits and recovery after subcortical stroke. Furthermore, the speech and language impairments following BG stroke in the LH and RH mirror the lexical-semantic/discourse dysfunction observed after cortical lesions to each hemisphere, thus reflecting the qualitatively different contributions of each hemisphere to language processing. We suggest that a substantial improvement of language dysfunction can be expected at 3 months after vascular damage to the BG although recovery may not be fully achieved at 1 year, being the impairment to language executive functions the most common residual deficit after nonthalamic subcortical stroke. Future studies with modern imaging techniques and more specific neuropsychological testing sensitive to RH language processing and frontal lobe dysfunction should further address the long-term recovery of language disorders in this pathology.

\section{Acknowledgments}

This study was supported by a national grant from the Spanish Government awarded to ARF (MICINN, PSI2011-29219). The writing of this work was completed while C.P. was in receipt of an IDIBELL predoctoral fellowship. The authors are grateful to all the participants for their permanent collaboration, commitment and continued participation in this follow-up study. The authors thank Julià Amengual for his helpful comments.

\section{Appendix A and B. Supplementary data}

Supplementary data related to this article can be found at http://dx.doi.org/10.1016/j.jneuroling. 2014.08.001.

\section{References}

Alexander, G. E., DeLong, M. R., \& Strick, P. L. (1986). Parallel organization of functionally segregated circuits linking basal ganglia and cortex. Annual Review of Neuroscience, 9, 357-381.

Alvarez, J. A., \& Emory, E. (2006). Executive function and the frontal lobes: a meta-analytic review. Neurospychology Review, 16, $17-42$.

Ardila, A., Ostrosky-Solís, F., \& Bernal, B. (2006). Cognitive testing towards the future: the example of semantic verbal fluency (ANIMALS). International Journal of Psychology, 41, 324-332.

Baddeley, A. D. (2003a). Working memory and language: an overview. Journal of Communication Disorders, 36, $189-208$.

Baddeley, A. D. (2003b). Working memory: Looking back and looking forward. Nature Reviews Neuroscience, 4, 829-839.

Baddeley, A. D., Gathercole, S., \& Papagno, C. (1998). The phonological loop as a language learning device. Psychological Review, $105,158-173$.

Baldo, J. V., \& Shimamura, A. P. (1998). Letter and category fluency in patients with frontal lobe lesions. Neuropsychology, 12, 256-267.

Benson, D. F., \& Ardila, A. (1996). Aphasia, a clinical perspective. New York: Oxford University Press.

Bird, H., Lambon Ralph, M. A., Patterson, K., \& Hodges, J. R. (2000). The rise and fall of frequency and imageability: noun and verb production in semantic dementia. Brain and Language, 73, 17-49.

Blake, M. L., Duffy, J. R., Myers, P. S., \& Tompkins, C. A. (2002). Prevalence and patterns of right hemisphere cognitive/ communicative deficits: retrospective data from an inpatient rehabilitation unit. Aphasiology, 16, 537-547.

de Boissezon, X., Démonet, J.-F., Puel, M., Marie, N., Raboyeau, G., Albucher, J.-F., et al. (2005). Subcortical aphasia: a longitudinal PET study. Stroke, 36, 1467-1473.

Bookheimer, S. (2002). Functional MRI of language: new approaches to understanding the organization of semantic processing. Annual Review of Neuroscience, 25, 155-188.

Breiman, R. S., Beck, J. W., Korobin, M., Glenny, R., Akwari, O. E., Heaston, D. K., et al. (1982). Volume determinations using computed tomography. American Journal of Roentgenology, 138, 329-333. 
Calero, M. D., Arnedo, M. L., Navarro, E., Ruiz-Pedrosa, M., \& Carnero, C. (2002). Usefulness of a 15-item version of the Boston Naming Test in neuropsychological assessment of low-educational elders with dementia. The Journals of Gerontology Series B: Psychological Sciences and Social Sciences, 57, 187-191.

Caplan, L. R., Schmahmann, J. D., Kase, C. S., Feldman, E., Basquis, G., Greenberg, J. P., et al. (1990). Caudate infarcts. Archives of Neurology, 47, 133-143.

Caplan, D., \& Waters, G. S. (1999). Verbal working memory and sentence comprehension. The Behavioral and Brain Sciences, 22, 77-94.

Cappa, S. F., Perani, D., Grassi, F., Bressi, S., Alberoni, M., Franceschi, M., et al. (1997). A PET follow-up study of recovery after stroke in acute aphasics.

Cohen, M. J., Riccio, C. A., \& Flannery, A. M. (1994). Expressive aprosodia following stroke to the right basal ganglia: a case report. Neuropsychology, 8, 242-245.

Copland, D. A., Chenery, H. J., \& Murdoch, B. E. (2000). Persistent deficits in complex language function following dominant nonthalamic subcortical lesions. Journal of Medical Speech-Language Pathology, 8, 1-14.

Crosson, B., Benefield, H., Cato, M. A., Sadek, J. R., Moore, A. B., Wierenga, C. E., et al. (2003). Left and right basal ganglia and frontal activity during language generation: contributions to lexical, semantic, and phonological processes. Journal of the International Neuropsychological Society, 9, 1061-1077.

Crosson, B., Sadek, J. R., Bobholz, J. A., Gökçay, D., Mohr, C. M., Leonard, C. M., et al. (1999). Activity in the paracingulate and cingulate sulci during word generation: an fMRI study of functional anatomy. Cerebral Cortex, 9, 307-316.

Cummings, J. L. (1993). Frontal-subcortical circuits and human behavior. Archives of Neurology, 50, 873-880.

Damasio, A. R., Damasio, H., Rizzo, M., Varney, N., \& Gersh, F. (1982). Aphasia with nonhemorrhagic lesions in the basal ganglia and internal capsule. Archives of Neurology, 39, 15-20.

D'Esposito, M., \& Alexander, M. P. (1995). Subcortical aphasia: distinct profiles following left putaminal hemorrhage. Neurology, $45,38-41$.

De Renzi, E., \& Faglioni, P. (1978). Normative data and screening power of a shortened version of the Token Test. Cortex, 14, 41-49.

Dubois, B., \& Pillon, B. (1996). Cognitive deficits in Parkinson's disease. Journal of Neurology, 244, 2-8.

Ferré, P., Ska, B., Lajoie, C., Bleau, A., \& Joanette, Y. (2011). Clinical focus on prosodic, discursive and pragmatic treatment for right hemisphere damaged adults: what's right? Rehabilitation Research and Practice, 2011.

Fridriksson, J., Richardson, J. D., Fillmore, P., \& Cai, B. (2012). Left hemisphere plasticity and aphasia recovery. NeuroImage, 60, 854-863.

Friederici, A. D. (2011). The brain basis of language processing: from structure to function. Physiological Reviews, 91,1357-1392.

Friedmann, N., \& Gvion, A. (2003). Sentence comprehension and working memory limitation in aphasia: a dissociation between semantic-syntactic and phonological reactivation. Brain and Language, 86, 23-39.

Fromm, D., Holland, A. L., Swindell, C. S., \& Reinmuth, O. M. (1985). Various consequences of subcortical stroke: prospective study of 16 consecutive cases. Archives of Neurology, 42, 943-950.

Godefroy, O., Dubois, C., Debachy, B., Leclerc, M., \& Kreisler, A. (2002). Vascular aphasias: main characteristics of patients hospitalized in acute stroke units. Stroke, 33, 702-705.

Goodglass, H., \& Kaplan, E. (1983). The assessment of aphasia and related disorders. Philadelphia: Lea \& Febiger.

Groenewegen, H. J., Berendse, H. W., Wolters, J. G., \& Lohman, A. H. (1990). The anatomical relationship of the prefrontal cortex with the striatopallidal system, the thalamus and the amygdala: evidence for a parallel organization. Progress in Brain Research, 85, 95-116.

Hickok, G. (2009). The functional neuroanatomy of language. Physics of Life Reviews, 6, 121-143.

Hillis, A. E. (2007). Aphasia. Progress in the last quarter of a century. Neurology, 69, 200-213.

Hillis, A. E., Barker, P. B., Wityk, R. J., Aldrich, E. M., Restrepo, L., Breese, E. L., et al. (2004). Variability in subcortical aphasia is due to variable sites of cortical hypoperfusion. Brain and Language, 89, 524-530.

Hillis, A. E., Wityk, R. J., Barker, P. B., Beauchamp, N. J., Gailloud, P., Murphy, K., et al. (2002). Subcortical aphasia and neglect in acute stroke: the role of cortical hypoperfusion. Brain, 125, 1094-1104.

Inase, M., Tokuno, H., Nambu, A., Akazawa, T., \& Takada, M. (1999). Corticostriatal and corticosubthalamic input zones from the presupplementary motor area in the macaque monkey: comparison with the input zones from the supplementary motor area. Brain Research, 833, 191-201.

Joanette, Y., \& Goulet, P. (1990). Narrative discourse in right brain-damaged right-handers. In Y. Joanette, \& H. Brownell (Eds.), Discourse ability and brain damage (pp. 131-153). New York: Springer.

Jodzio, K., Lojek, E., \& Bryan, K. (2005). Functional and neuroanatomical analysis of extralinguistic disorders in right hemisphere damaged patients. Psychology of Language and Communication, 9, 55-73.

Just, M. A., \& Carpenter, P. A. (1992). A capacity theory of comprehension: individual differences in working memory. Psychological Review, 99, 122-149.

Kuljic-Obradovic, D. C. (2003). Subcortical aphasia: three different language disorder syndromes? European Journal of Neurology, $10,445-448$.

Kumral, E., Evyapan, D., \& Balkir, K. (1999). Acute caudate vascular lesions. Stroke, 30, 100-108.

Lewis, S. G. J., Dove, A., Robbins, T. W., Barker, R. A., \& Owen, A. M. (2003). Cognitive impairments in early Parkinson's disease are accompanied by reductions in activity in frontostriatal neural circuitry. Journal of Neuroscience, 23, 6351-6356.

Liang, C. L., Chang, H. W., Lu, K., Lee, T. C., Liliang, P. C., Lu, C. H., et al. (2001). Early prediction of aphasia outcome in left basal ganglia hemorrhage. Acta Neurologica Scandinavica, 103, 148-152.

Mecklinger, A., Bosch, V., Gruenewald, C., Bentin, S., \& von Cramon, D. Y. (2000). What have Klingon letters and faces in common? An fMRI study on contentspecific working memory systems. Human Brain Mapping, 11, 146-161.

Mega, M. S., \& Alexander, M. P. (1994). Subcortical aphasia: the core profile of capsulostriatal infarction. Neurology, 44,1824-1829.

Meinzer, M., Elbert, T., Wienbruch, C., Djundja, D., Barthel, G., \& Rockstroh, B. (2004). Intensive language training enhances brain plasticity in chronic aphasia. BMC Biology, 2, 20.

Metter, E. J., Jackson, C., Kempler, D., Riege, W. H., Hanson, W. R., Mazziotta, J. C., et al. (1986). Left hemisphere intracerebral hemorrhages studied by (F-18)-fluorodeoxyglucose PET. Neurology, 36, 1155-1162. 
Metter, E. J., Riege, W. H., Hanson, W. R., Kuhl, D. E., Phelps, M. E., Squire, L. R., et al. (1983). Comparison of metabolic rates, language, and memory in subcortical aphasias. Brain and Language, 19, 33-47.

Middleton, F. A., \& Strick, P. L. (2000). Basal ganglia and cerebellar loops: motor and cognitive circuits. Brain Research Reviews, 31, $236-250$.

Mitrushina, M., Boone, K. B., Ramazi, J., \& D'Elia, L. F. (2005). Handbook of normative data for neuropsychological assessment. New York: Oxford University Press.

Montoya, A., Price, B. H., Menear, M., \& Lepage, M. (2006). Brain imaging and cognitive dysfunctions in Huntington's disease. Journal of Psychiatry and Neuroscience, 31, 21-29.

Moore, A. B., Li, Z., Tyner, C. E., Hu, X., \& Crosson, B. (2013). Bilateral basal ganglia activity in working memory. Brain \& Language, $125,316-323$.

Murteira, A., \& Santos, M. E. (2012). Language processing in right hemisphere stroke patients: response speed and quality. Aphasiology, 27, 145-156.

Nadeau, S. E., \& Crosson, B. (1997). Subcortical aphasia. Brain and Language, 58, 355-402.

Naeser, M., Alexander, M. P., Helm-Estabrooks, N., Levine, H. L., Laughlin, S. A., \& Geschwind, N. (1982). Aphasia with predominantly subcortical lesion sites: description of three capsular/putaminal aphasia syndromes. Archives of Neurology, 39, $2-4$.

Naeser, M. A., Palumbo, C. L., Helm-Estabrooks, N., Stiassny-Eder, D., \& Albert, M. (1989). Severe nonfluency in aphasia: the role of the medial subcallosal fasciculus plus other white matter pathways in recovery of spontaneous speech. Brain, 112, 1-38.

Oldfield, R. C. (1971). The assessment and analysis of handedness: the Edinburgh inventory. Neuropsychologia, 9, 97-113.

Owen, A. M. (2004). Cognitive dysfunction in Parkinson's disease: the role of frontostriatal circuitry. The Neuroscientist, 9, 1-13.

Parent, A. (1990). Extrinsic connections of the basal ganglia. Trends in Neurosciences, 13, 254-258.

Peña-Casanova, J. (2005). Integrated neuropsychological exploration program - Barcelona test revised. Barcelona: Masson.

Petrides, M. (2000). Dissociable roles of mid-dorsolateral prefrontal and anterior inferotemporal cortex in visual working memory. Journal of Neuroscience, 20, 7496-7503.

Petrides, M. (2005). Lateral prefrontal cortex: architectonic and functional organization. Philosophical Transactions of the Royal Society of London, Series B, Biological Sciences, 360, 781-795.

Radanovic, M., Mansur, L. L., Azambuja, M. J., Porto, C. S., \& Scaff, M. (2004). Contribution to the evaluation of language disturbances in subcortical lesions: a piloty study. Arquivos de Neuro-Psiquiatria, 62, 51-57.

Radanovic, M., \& Scaff, M. (2003). Speech and language disturbances due to subcortical lesions. Brain and Language, 84, $337-352$.

Schlaug, G., Marchina, S., \& Norton, A. (2009). Evidence for plasticity in white matter tracts of chronic aphasic patients undergoing intense intonation-based speech therapy. Annals of the New York Academy of Sciences, 1169, 385-394.

Schmahmann, J. D., \& Pandya, D. N. (2008). Disconnection syndromes of basal ganglia, thalamus, and cerebrocerebellar systems. Cortex, 44, 1037-1066.

Stuss, D. T., \& Levine, B. (2002). Adult clinical neuropsychology: lessons from studies of the frontal lobes. Annual Review of Psychology, 53, 401-433.

Su, C. Y., Chen, H. M., Kwan, A. L., Lin, Y. H., \& Guo, N. W. (2007). Neuropsychological impairment after hemorrhagic stroke in basal ganglia. Archives of Clinical Neuropsychology, 22, 465-474.

Troyer, A. K., Moscovitch, M., \& Winocur, G. (1997). Clustering and switching as two components of verbal fluency: evidence from younger and older healthy adults. Neuropsychology, 11, 138-146.

Vallar, G., \& Baddeley, A. D. (1987). Phonological short-term store and sentence processing. Cognitive Neuropsychology, 4, 417-438.

Vallar, G., Perani, D., Cappa, S. F., Messa, C., Lenzi, G. L., \& Fazio, F. (1988). Recovery from aphasia and neglect after subcortical stroke: neuropsychological and cerebral perfusion study. Journal of Neurology, Neurosurgery and Psychiatry, 51, 1269-1276.

Wallesch, C. W., Johannsen-Horbach, H., Bartels, C., \& Herrmann, M. (1997). Mechanisms of and misconceptions about subcortical aphasia. Brain and Language, 58, 403-409.

Watson, C., Andermann, F., Gloor, P., Jones-Gotman, M., Peters, T., Evans, A., et al. (1992). Anatomical basis of amogdaloid and hippocampal volume measurement by magnetic resonance imaging. Neurology, 42, 1743-1750.

Zgaljardic, D. J., Borod, J. C., Foldi, N. S., \& Mattis, P. (2003). A review of the cognitive and behavioral sequelae of Parkinson's disease: relationship to frontostriatal circuitry. Cognitive and Behavioral Neurology, 16, 193-210. 